\title{
ANTONIO DA SILVA JARDIM (1860-1891) E A DIVULGAÇÃO DO "NOVO E CIENTÍFICO" MÉTODO "JOÃO DE DEUS" PARA O ENSINO DA LEITURA E ESCRITA
}

\author{
ANTONIO DA SILVA JARDIM (1860-1891) AND THE DISSEMINATION \\ OF THE "NEW AND SCIENTIFIC" METHOD "JOÃO DE DEUS" FOR TEACHING \\ READING AND WRITING
}

Franciele Ruiz Pasquim

Faculdades FACCAT

francielepasquim@gmail.com

\section{RESUMO}

Com o objetivo compreender o pensamento do professor Antonio da Silva Jardim (1860-1891) sobre o ensino da leitura e da escrita, enfoca-se, neste artigo, o documento Reforma do ensino da lingua materna (1884). Trata-se da versão impressa do resumo da conferência proferida por Silva Jardim, como professor da Primeira Cadeira - "Grammatica e Língua Nacional", da Escola Normal de São Paulo. Embora menor em sua produção, a questão da leitura era parte integrante e importante das ideias de Silva Jardim para a nação brasileira pautada nos ideais da República. Para ele, a formação de professores deveria compreender a "parte pedagógica" e a "parte prática", ou seja, a observarção e a aplicação do "novo" e "científico" método da palavração nas escolas primárias anexas a Escola Normal.

Palavras-chave: Antonio da Silva Jardim; História do ensino inicial de leitura e escrita; História da Formação de professores; História da Educação.

\begin{abstract}
In order to contribute of the thoughts of teacher Antonio da Silva Jardim (1860-1891) on the teaching reading and writing. In this article focuses the document Reforma do ensino de lingua materna (1884), which contains the printed version $f$ the summary of the conference issued by Silva Jardim, as a head teacher- "Gramática e Língua nacional", from Escola Normal de São Paulo. It was found that the reform proposed by Silva Jardim, although poorly explored and apparently lowest in its production, was integral of their ideias for the Brazilian nation by ideals of the Republic. For him, the development of teachers should include the "pedagogical part" and the "practice part" in wich students of Escola Normal of São Paulo ought to observe and apply the "new" and "scientific" palavração method.
\end{abstract}

Key-words: Antonio da Silva Jardim; History of teaching reading and writing; History of teacher education; History of Education. 


\section{Introdução}

Há pouco mais de um século, Antonio da Silva Jardim (1860-1891), o "herói da República”, ocupa lugar de prestígio nos estudos sobre História do Brasil em que se enfatizam, principalmente, sua ação e atuação política frente ao Abolicionismo, Republicanismo, Positivismo e Cientificismo, questões sociais centrais de sua época.

Num balanço dos trabalhos acadêmicos, biografias e memórias sobre Silva Jardim, pode-se observar que há um destaque maior para sua atuação como adepto do positivismo e defensor da instauração do regime político republicano. Lembrado e destacado por seus contemporâneos e pósteros pelo brilhantismo de sua atuação política em prol da formação de uma nação brasileira, os estudiosos de Silva Jardim pertencem a diferentes áreas do conhecimento, tais como, história geral, sociologia, história da educação e nas últimas décadas na história do ensino da leitura e escrita no Brasil.

Somente nas três últimas décadas do século XX é que se pode observar o aumento significativo da produção acadêmico-científica brasileira sobre história da educação e, em particular, no campo da história da alfabetização no Brasil. Logo, os pesquisadores motivados em buscar soluções para os problemas históricos relacionados ao ensino inicial da leitura e escrita passam a desenvolver pesquisas históricas em educação, contribuindo sobremaneira para a constituição e consolidação desse campo de conhecimento. (MORTATTI, 2000a; 2011).

No âmbito desse campo de conhecimento, destacam-se o estudo de Magnani (1997)/Mortatti (2000) considerado um "manancial de inúmeros estudos" (SOARES, 2000a), que suscitou novas possibilidades de pesquisa e contribuiu para a compreensão de muitos aspectos ainda pouco explorados da história do ensino de leitura e escrita no Brasil.

Essas pesquisas sobre história da alfabetização têm como matriz teórica o livro Os sentidos da alfabetização: São Paulo/1876-1994 (MORTATTI, 2000a)ํ․ Nesse livro, a autora aborda a história da alfabetização no Brasil em quatro momentos², com ênfase no estado de São Paulo, no período entre 1876 e 1994, nos quais destaca as "permanências e rupturas" quanto ao ensino inicial da leitura e da escrita.

É no "primeiro momento da história da alfabetização" que se situa a proposição deste artigo, em especial os aspectos relacionados ao pensamento do professor, advogado, político, propagandista, positivista e republicano, Silva Jardim, a sua atuação como professor da Escola Normal de São Paulo e a sua contribuição quanto à divulgação da Cartilha Maternal ou Arte da Leitura (1876), do poeta português João de Deus. De acordo com Mortatti (2000a), a partir da atuação desse professor uma tradição é fundada em que "[...] ensino da leitura envolve necessariamente uma questão de método" (MORTATTI, 2000a, p.73).

O objetivo deste artigo é apresentar no âmbito da produção sobre Silva Jardim o que permaneceu silenciado por muitos estudiosos, a preocupação de Silva Jardim com o ensino de leitura e escrita que, embora considerada uma questão menor e menos explorada por muitos estudiosos, foi parte integrante de atuação política em prol da instauração da República e da formação da nação brasileira.

1 Esse livro é resultante da tese de livre docência de Magnani (1997).

2 O primeiro momento é caracterizado pela disputa entre os partidários do "novo" método da palavração e os partidários dos métodos "tradicionais" ou "sintéticos" (soletração e silabação). O segundo momento - "A institucionalização do método analítico" (entre 1890 e meados da década de 1920) é caracterizado pela disputa entre os defensores do "novo" método analítico (palavração, sentenciação ou da historieta) e os partidários dos métodos sintéticos (em especial da silabação). O terceiro momento - "A alfabetização sob medida" (entre meados da década de 1920 e final da década de 1970) é caracterizado pela hegemonia dos testes ABC, formulados por Manoel Bergström Lourenço Filho e divulgados no livro Testes $A B C$ : para verificação da maturidade necessária à aprendizagem da leitura e da escrita, publicado em 1934. quarto momento - "Alfabetização: construtivismo e a desmetodização" (entre início da década de 1980 e os dias atuais) é caracterizado pela disputa entre os defensores do pensamento construtivista de Emilia Ferreiro e os defensores dos "tradicionais métodos" (analíticos, sintéticos ou mistos) (MORTATTI, 2000a). 
Para contemplar esse objetivo, apresentarei os resultados da análise da configuração textual do documento Reforma do ensino da lingua materna (1884), de Antonio da Silva Jardim. Nesse documento estão contidos os saberes necessários para a formação do professor primário quanto ao ensino da leitura e da escrita relacionada com o movimento de idéias relativo à educação no período imperial brasileiro.

\section{Antonio da Silva Jardim (1860-1891): o "herói da República"}

Antonio da Silva Jardim nasceu durante o período Imperial $^{3}$ brasileiro, no dia 16 de agosto de 1860, na cidade de Capivari (RJ), atual município de Silva Jardim4.

Filho de Gabriel da Silva Jardim ${ }^{5}$ e de Felismina Leopoldina de Mendonça Jardim, ambos eram "[...] pequenos lavradores na então província do Rio de Janeiro" (Leão, 1895: p. 4), Silva Jardim teve contato com as primeiras letras na infância. Seu pai, Gabriel da Silva Jardim, era professor de primeiras letras e ensinava os rudimentos da leitura e da escrita em sua própria casa. E, conforme apontam seus biógrafos, Silva Jardim, por ter desenvolvido o gosto pelos estudos, aos 11 de idade já ensinava os colegas de classe quando na ausência de seu pai.

Ainda durante sua infância, apesar das dificuldades econômicas pelas quais o seu pai passava Silva Jardim, por ser um aluno muito dedicado, "[...] foi para Niterói fazer os estudos secundários. Ali contraiu varíola benigna, que lhe deixou marcas no rosto por toda vida. Após a cura, retomou os estudos no colégio secundário Silva Pontes [...]" (GUZZO, 2003, p.12).

Em 1874, com 14 anos, Silva Jardim foi estudar no Colégio Mosteiro de São Bento ${ }^{6}$, em Niterói (RJ), onde recebeu a educação católica. No ano seguinte, em 1875, estudou no Externato "Jasper"7, enfrentando dificuldades financeiras que ameaçavam sua permanência nessa instituição. Por esse motivo, a fim de complementar a renda familiar e pagar as despesas com seus estudos, Silva Jardim auxiliou o ex-professor Jasper L. Harben ${ }^{8}$ nas aulas particulares de inglês que eram ministradas por esse professor (GUZZO, 2003, p.13).

Entre 1875 e 1878, Silva Jardim iniciou os estudos preparatórios para o curso de Direito no Rio de Janeiro (RJ) e teve como colega o poeta Raimundo Corrêa ${ }^{9}$. No ano de 1878, mudou-se para São Paulo e ingressou com 18 anos incompletos na Faculdade de Direito de São Paulo (SP).

O ingresso na Faculdade de Direito de São Paulo representou um marco na trajetória intelectual de Silva Jardim, pois, além de confirmar sua notável capacidade e inteligência para os estudos, seu ingresso na vida acadêmica contribuiu para definir seu perfil ideológico e político.

\footnotetext{
3 No Brasil, Império é o período compreendido entre a independência em 1822 e a proclamação da República, em 1889. De acordo com Vainfas (2008, p.358) o Império foi "[...] a materialização de um projeto político que, na sua gênese, sequer rompia o estatuto colonial do Brasil, embora o colocasse em posição estratégica no mundo ultramarino português".

4 No dia 09 de agosto de 2010, o município de Silva Jardim comemorou o sesquicentenário de nascimento de seu patrono. E, durante as comemorações foram organizadas exposições e premiação dos vencedores dos projetos "Meu bairro" e "História da minha cidade". Ainda teve premiação das melhores redações sobre "Os republicanos".

5 Gabriel Jardim "[...] nascido em 2 de julho de 1841, casou-se aos 18 annos, entregando-se aos misteres ruraes até 1865, em que por instancia de amigos fundou uma escola particular, que aproveitou á infancia de Silva Jardim" (LEÃO, 1895, p.5).

6 O Colégio de São Bento foi fundado pelos monges do mosteiro de São Bento, em 1858. Trata-se de ma instituição educativa católica beneditina para meninos. Disponível em: http://www.osb.or.br/mosteiro/index.php. Acesso em: 22 de novembro de 2012.

7 Não localizei informações, até o momento, sobre essa instituição.

8 Jasper L. Harber foi diretor do Externado "Jasper" e autor do livro Prosódia Ingleza: novo methodo para aprender a pronunciar e fallar com facilidade todas as palavras da lingua ingleza, publicado em 1878. (Revista ilustrada, 1878, p.7).

9 Raimundo Corrêa nasceu em 13 de maio de 1859 no Maranhão e morreu em 13 de setembro de 1911 em Paris. Mais informações disponíveis em: http://www.osb.org.br/mosteiro/index.php. Acesso em: 9 de agosto de 2012.
} 
No início do Império brasileiro, a religião impunha seus valores conforme interesse dos governantes, mas ideias contrárias a essa união estavam fervilhando entre os jovens, principalmente entre os alunos da Faculdade de Direito de São Paulo. Nessa instituição, circulavam entre os futuros bacharéis as ideias decorrentes da separação entre Estado e Igreja, pautados no Positivismo de Comte e no cientificismo do século XIX.

Implantada em 1827, poucos anos após a Independência do Brasil, a Faculdade de Direito de São Paulo contribuiu para o desenvolvimento da Nação e representava a elite intelectual e política do país. Além disso, foi um polo de formação de bacharéis, muitos deles se tornaram futuros governantes e administradores públicos. ${ }^{10}$

Foi também no clima da vida acadêmica que Silva Jardim conheceu e aderiu aos preceitos do Positivismo de Auguste Comte ${ }^{11}$. Inicialmente, Silva Jardim esteve vinculado aos positivistas ortodoxos que "[...] queriam um presidente forte, um cérebro ativo na chefia do Estado" (BOSI, 1992, p.237), porém, algumas tensões de ordem política e social o fizeram o fizeram optar pelas ideias do Evolucionismo ${ }^{12}$ que, assim como ele, defendiam "reformas espontâneas, lentas e graduais" (BOSI, 1992, p. 237).

Em 1878, quando cursava o primeiro ano de faculdade, Silva Jardim conheceu Ana Margarida de Andrada, filha de Martim Francisco Ribeiro de Andrada ${ }^{13}$, que era conselheiro e professor de Direito Eclesiástico, da Faculdade de Direito de São Paulo.

O relacionamento de Silva Jardim com a filha do Conselheiro Andrada possibilitou ampliar ainda mais seu círculo de amizades e, por esse motivo, conheceu o professor Inglês de Sousa ${ }^{14}$. O estabelecimento de uma relação de amizade com essa importante figura da época rendeu a Silva Jardim algumas ascensões importantes, como, por exemplo, sua nomeação, no dia 2 de agosto de 1880, para secretário e professor da aula primária do sexo masculino à Escola Normal anexa à Escola Normal de São Paulo (SP) e convidado a ser redator do jornal Tribuna liberal de São Paulo.

A atuação de Silva Jardim como secretário da Escola Normal e como professor do Curso Primário Anexo a essa instituição contribuiu para suas aspirações e propósitos em prol da modernização da educação do Brasil. Nessa instituição, era responsável por formar professores primários para o ensino da leitura e da escrita; estava aí a possibilidade de combater o analfabetismo no país. (MORTATTI, 2000a).

Como professor da seção masculina do Curso Primário Anexo à Escola Normal, Silva Jardim, motivado pelas inovações educacionais da época, "[...] tornou-se partidário da cartilha de João de Deus, que se ajustava às suas concepções positivas. O livro ensinava a ler pelo método da palavração, isto é, não por meio de sílabas, nem soletrando, e sim logo através de palavras completas, das mais simples às mais complexas". (QUEIROZ, 1967, p. 50).

10 Essas informações foram extraídas da seção "História" do site da Faculdade de Direito de São Paulo. Disponível em: http//:www.diretiro. usp.br/faculdade/index_faculdadehistoria01.php. Acesso em: 10 de dezembro de 2012.

11 Isisdore- Auguste-Marie Xavier Comte nasceu em Montpellier em 19 de janeiro de 1789 e faleceu em Paris no dia 5 de setembro de 1857. A essência do pensamento comtiano é a "humanidade, ciência, síntese e fé". (RIBEIRO, 1988, p.8)

12 Como se sabe, o Evolucionismo é uma corrente filosófica que se desenvolveu na Europa, ao longo do século XIX, a partir dos estudos de Jean-Baptiste de Lamarck (1744-1829) e Charles Darwin (1809-1882). Embora haja diferentes vertentes do Evolucionismo, todas elas partem do princípio de que a evolução (adaptação às alterações ocorridas no meio ambiente) é uma condição natural de todos os seres. Além de Darwin e Lamarck, outros importantes representantes do Evolucionismo foram: Hebert Spencer (1820-1903) e Teilhard de Chardin (1881-1955) (JAPIASSÚ; MARCONDES, 2008).

13 Martim Francisco Ribeiro de Andrada diplomou-se em filosofias e matemáticas, na Universidade de Coimbra (Portugal). Em 1821 inicia sua carreira política como secretário do governo provisório de São Paulo. Em 1822 foi ministro da fazenda. Em 1823 foi eleito como deputado de sua província para a Assembleia Constituinte de 1823. Faleceu em 1844. (VAINFAS, 2008, p.527).

14 Herculano Marcos Inglez de Sousa nasceu em 1853 na cidade de Óbtidos no estado do Pará e morreu em 1918 no Rio de Janeiro. Formado em Direito, foi presidente do Espírito Santo e do Maranhão. Foi professor da Universidade Federal do Rio de Janeiro e membro fundador da Academia Brasileira de Letras. (MOISÉS, 2001, p.42). 
Os cargos ocupados por Silva Jardim na Escola Normal muito contribuíram para sua permanência na faculdade de Direito, pois, além de pagar seus estudos, ele podia ajudar seus pais. Assim, em abril de 1882, aos 22 anos de idade, Silva Jardim formou-se bacharel em Ciências Sociais e Jurídicas pela Faculdade de Direito de São Paulo.

Nesse mesmo ano, Silva Jardim foi convidado por Herculano Marcos Inglez de Sousa, o então presidente da província do Espírito Santo, para propagar o "novo método" de ensino - o método "João de Deus" - por meio de conferências públicas sobre as vantagens desse método para o ensino da leitura, que já utilizara quando ainda era professor do Curso Primário Anexo à Escola Normal de São Paulo.

Entre os dias 18 e 28 de julho de 1882, Silva Jardim permaneceu em Vitória, capital da província do Espírito Santo, para divulgar esse novo método de ensino, conforme as cláusulas do contrato acordado com Inglês de Sousa.

Além das conferências, Silva Jardim ensinava em casas particulares e promovia cursos diários para ensinar os professores a ensinar leitura pelo método "João de Deus". Essas conferências proferidas por Silva Jardim na província do Espírito Santo davam-Ihe grande prestígio para sua atuação como professor e divulgador do método "João de Deus"; por outro lado, Inglês de Sousa recebeu críticas negativas por tê-lo convidado a proferir essas conferências nessa província.

O motivo pelo qual Inglês de Sousa convidou Silva Jardim para divulgar o método "João de Deus" na província do Espírito Santo estava relacionado a dois fatores: Inglês de Sousa já conhecia o trabaIho realizado por Silva Jardim no Curso Primário Anexo à Escola Normal; e Inglês de Sousa considerava o "método de primeiras letras" (soletração), adotado pela província do Espírito Santo, "defeituoso e atrasado" (GONTIJO, 2012 p. 82)

Diante desses fatores, Inglês de Sousa justificou a ida de Silva Jardim atribuindo a esse professor a função de divulgar um método eficaz para o ensino da leitura, que pudesse contribuir para a reforma da instrução pública primária na província do Espírito Santo.

Depois de atuar na província do Espírito Santo, de volta a São Paulo, em outubro de 1882, Silva Jardim se inscreveu para o concurso para o provimento da Cadeira de "Grammatica e Lingua Nacional" da Escola Normal de São Paulo. Nesse concurso se inscreveram, além de Silva Jardim, Manoel José Trancoso e Júlio Ribeiro (D’AVILA, 1946, p. 91). As inscrições para esse concurso encerraram-se em março de 1883 e, após a realização das provas, nesse mesmo ano, Silva Jardim foi aprovado no dia 26 de abril de 1884 e nomeado professor vitalício da Cadeira de "Gramática e Lingua Nacional" da Escola Normal de São Paulo.

No mesmo ano de seu ingresso como professor na Escola Normal, em $1^{\circ}$. de maio de 1883, Silva Jardim casou-se com Ana Margarida Bueno de Andrada e, após nove meses de casado, nasceu seu primeiro filho, cujo nome também era Antonio da Silva Jardim. Além desse filho, Silva Jardim teve outros dois, Condorcet e Clotilde Sofia, que morreram precocemente (Fernandes, 2008:71). Segundo Fernandes (2008, p.71), “[...] a valorização pela família, a admiração pelo jacobinismo a la Danton e à filosofia de Condorcet, bem como a filiação ao Positivismo estão expressos nos três filhos".

Concomitantemente à atuação como professor da Escola Normal de São Paulo, Silva Jardim foi diretor da Escola Neutralidade ${ }^{15}$ na cidade de Santos, na província de São Paulo. Essa escola foi

15 A Escola Neutralidade era destinada a crianças e a adolescentes de 7 e 18 anos e seu ensino era pautado no método intuitivo e concreto. A esse respeito, ver, especialmente, Hilsdorf (1986). 
fundada por Silva Jardim, juntamente com o professor João Kopke ${ }^{16}$, no ano de 1884. Com a fundação dessa instituição de ensino, Silva Jardim

[...] pretendia livremente pôr em prática os seus métodos pedagógicos e desenvolvê-los. Perturbadora novidade para época, a escola era laica. Seu nome, a Escola Neutralidade, tencionava indicar justamente este caráter "neutro" em face da religião. (QUEIROZ, 1967, p.52).

Contudo, nesse período, deixou o cargo de diretor e sócio da Escola Neutralidade e, no ano seguinte, em 1887, filiou-se ao Clube Republicano ${ }^{17}$ de Santos. A partir de sua adesão a esse clube, iniciou suas conferências sobre o abolicionismo e as possibilidades de uma República brasileira, uma vez que ele foi militante e combatente contra a escravidão e lutou em sociedades secretas que libertavam escravos negros. (QUEIROZ, 1967; GUZZO, 2003).

Os anos de 1888 e 1889 foram marcados por um período de efervescência política na vida de Silva Jardim. Nessa época, ele passou a desempenhar o papel de propagandista da República, propriamente brasileira. Após a Proclamação da República em 15 de novembro de 1889, Silva Jardim, em uma de suas viagens à Itália, ao visitar o Vulcão Vesúvio, caiu em uma das crateras desse vulcão e morreu em $1^{\circ}$. de julho de 1891. Sua morte representou, segundo muitos estudiosos, "a morte de um republicano e o nascimento da República".

\section{Silva Jardim e a Reforma do ensino de lingua materna (1884)}

Em 1882, após a exoneração do professor Vicente Mamede de Freitas ${ }^{18}$, do cargo de professor da $1^{\text {a }}$. Cadeira da Escola Normal de São Paulo foi aberto concurso público para o preenchimento desse cargo. Depois do encerramento das inscrições, em 1883, inscreveram-se para concorrer ao cargo os professores: Manoel José da Lapa Trancoso, Silva Jardim e Júlio Ribeiro. Após a realização das provas, ocorridas em 1883, Silva Jardim foi aprovado no concurso (D’AVILA, 1946).

Silva Jardim foi empossado em 1884 professor vitalício da 1. Cadeira - "Grammatica e Lingua Nacional" - da Escola Normal de São Paulo. Após assumir esse cargo, em atendimento ao Regulamento de 30 de junho de 1880, Silva Jardim proferiu, no dia 21 de abril de 1884, a Conferência Reforma do ensino da lingua materna, na qual apresentou sua proposta para o ensino da leitura e da escrita aos alunos da Escola Normal de São Paulo e às demais autoridades escolares presentes.

16 João Kopke nasceu em 1852, em Petrópolis, na Província do Rio de Janeiro. Bacharelou-se em Direito pela Academia de Direito de São Paulo, em 1875. Após atuar três anos na área do direito, como promotor e advogado, e abandonou a magistratura para se dedicar às questões relativas à Educação (Instrução Pública). No âmbito de sua atuação profissional. Entre 1881 e 1883, foi professor do Colégio Culto à Ciência e do Colégio Florence, ambos de Campinas (SP); em 1878, foi nomeado professor substituto do Curso Anexos à Academia de Direito de São Paulo, voltando a atuar nesse cargo, entre 1883 e 1885; fundou, em 1884, com Silva Jardim, a Escola Primária Neutralidade, na capital da Província de São Paulo, tendo atuado como diretor dessa escola até 1886; e, em 1888, mudou-se definitivamente para o Rio de Janeiro, onde fundou a Escola Primária Neutralidade - Instituto Henrique Kopke (MORTATTI, 2002). Para informações mais detalhadas sobre o Kopke, ver: Mortatti (2002)

17 O Clube Republicano de Santos era marcado por uma política abolicionista e "[...] que nunca abandonou a causa da libertação dos escravos às suas ideias progressistas" (GUZZO, 2003, p.16).

18 Vicente Mamede de Freitas nasceu em 17 de agosto de 1836. Em 1855, formou-se bacharel de Direito Cívico. Foi diretor do Colégio "Culto à Ciência" e fundador do colégio na Ladeira do Porto Geral. Como inspetor geral da Instrução Pública, inaugurou, em 2 de agosto de 1880, a Escola Normal de São Paulo. Por decreto de 5 de setembro de 1882, foi aprovado em concurso e nomeado lente substituto e depois diretor da Faculdade de Direito de São Paulo.Por esse motivo exonerou-se da cadeira de "Grammatica e Lingua Nacional". Faleceu em 9 de agosto de 1908. Informações extraídas do site da Faculdade de Direito. Disponível em: http://www.direito.usp.br/faculdade/diretores/ index_faculdade_diretor_11.php. Acesso em: 13 de novembro de 2013. 
Essa conferência foi proferida em cumprimento do artigo $8^{\circ}$. do Regulamento de $1880 \ldots$ da Escola Normal de São Paulo, que prescrevia a realização de conferências públicas nas quais os professores deveriam abordar temas sobre a instrução pública brasileira. Por esse motivo, o professor Silva Jardim, na ocasião, proferiu a Conferência pública à Congregação dos professores da Escola Normal. O professor, conforme prescrito no Regulamento de 1880 ... poderia ser convocado a qualquer momento pelo presidente da província, a fim de explanar, sobre a matéria que lecionava.

A versão escrita do resumo dessa Conferência foi divulgado aos alunos da Escola Normal como um modelo de ensinar a leitura e está organizada em três tópicos. Ao longo da Conferência de Silva Jardim apresenta, dentre os principais aspectos, os relativos à função e ensino da língua, à formação do professor primário, ao ensino da gramática e ao ensino da leitura pelo método da palavração (PASQUIM, 2013, p.78).

No primeiro tópico, Silva Jardim destaca a "função social" da linguagem que, segundo ele, foi construída para a comunicação entre os homens. Por isso, para Silva Jardim, é pela linguagem "[...] que os entes colletivos, a familia, a pátria, se nos revelam, influindo na nossa natureza: os esforços isolados dos sábios seriam incapazes de formar uma lingua". (Silva Jardim, 1884, p.9-10). E é por meio da linguagem que foi possível a formação da língua como instrumento de transmissão das "[...] grandes noções scientificas, abstractas e concretas, sobre o mundo, a sociedade e o homem" (JARDIM, 1884, p. 10).

No segundo tópico, Silva Jardim apresenta as seguintes questões sobre o ensino da língua materna: o que ensinar (conteúdos)?; como ensinar? (método); e para que ensinar? (finalidade). Segundo esse professor, o ensino espontâneo é a base para o ensino mais sistemático da língua materna que é aprendida pela criança com seus familiares e vai sendo aprimorada. Silva Jardim atribui a adequação do método da palavração para o ensino da leitura ao modo espontâneo com que se aprende a falar, como se pode observar no seguinte trecho: “[...] meus senhores, só se vence pelo aperfeiçoamento; como aprendemos a falar? falando as palavras; como aprenderemos a lêr? é claro que lendo essas mesmas palavras".

No terceiro tópico, Silva Jardim expõe sua preocupação com a situação, à época, do ensino da língua, criticando o método de ensino utilizado, o que tornava ainda pior o ensino da gramática; além dessas preocupações, enfatiza, sobremaneira, a formação do professor primário na Escola Normal de São Paulo.

Para esse professor, por fim, o ensino inicial da leitura estava fortemente vinculado ao desenvolvimento da língua oral ("leitura em voz alta", "pronúncia", "conversação", recitação). No que se refere ao ensino da escrita, este estava ainda fortemente vinculado ao treino da caligrafia, mas já disseminavam exercícios de composição escrita, o que representava um importante avanço para a época.

\section{Silva Jardim e a formação de professores na Escola Nomal de São Paulo, na década de 1880.}

Considerando a classificação utilizada por grande parte dos pesquisadores da História da educação brasileira, apresentarei ao longo deste tópico, aspectos relativos às três fases da Escola Normal de São Paulo ${ }^{19}$, que correspondem ao seu funcionamento nos seguintes períodos: 1846 a 1867 (Criação); 1875 a 1878 (Reabertura); e 1880 a 1890 (Reforma). Ressalto que, com relação à terceira fase da Escola Normal de São Paulo, destacarei até o período em que Silva Jardim lecionou nessa instituição.

19 A Escola Normal de São Paulo teve diferentes denominações: "Escola Normal da Capital", "Escola Normal Secundária", "Escola Normal da Praça". Em 1911, a Escola Normal da Capital passou, pela Lei n. 1341 de 16-12, à denominação de Escola Normal Secundária. A respeito da história dessa escola, ver, especialmente, o trabalho pioneiro de Tanuri (1979), Hilsdorf (2008). Reis Filho (1995) e Dias (2002, 2008). 
Segundo Reis Filho (1995), pela necessidade de ensinar a ler e a escrever as crianças do Império e pela ausência de professores para a concretização desse anseio, foi criada em 16 de novembro de 1846, em cumprimento a Lei n 34, de 16 de março desse ano, a Escola Normal de São Paulo, cujo objetivo principal era o de formar professores primários para o ensino das primeiras letras. Contando com apenas com um professor, a Escola Normal de São Paulo era exclusivamente para o sexo masculino. Depois de dois anos de estudos, os alunos seriam considerados professores primários.

Com relação ao conteúdo que os alunos normalistas aprenderiam para depois poderem ensinarem nas "escolas de primeiras letras", de acordo com Reis Filho (1995, p.150), eram ministradas disciplinas, tais como: "Lógica, Gramática, Língua Nacional, Aritmética, Geometria Prática, Caligrafia, Doutrina Cristã e Métodos e Processos de Ensino", as quais, segundo o autor, eram disciplinas que "[...] o professor deveria ensinar na escola primária. Tratava-se de um curso de continuação ao ensino elementar, representando nada mais do que seu aprofundamento" (REIS FILHO, 1995, p.150).

A Escola Normal de São Paulo não conseguia desempenhar sua real função concernente à formação de professores no Império e foi fechada em 1867 e somente depois de oito anos foi reaberta. Segundo Reis Filho (1995),

[...] em fevereiro de 1875, com ata e discurso, foi inaugurada a segunda Escola Normal de São Paulo, criada no ano anterior pela Lei $n^{\circ}$. 9, de fevereiro de. Foi instalada no Edifício da Faculdade de Direito. Era um curso de dois anos e, como a primeira Escola Normal de São Paulo, só para homens (p.150).

Na primeira fase, essa instituição contava com duas cadeiras e um curso apenas para homens. Em 1876, um ano após sua reabertura, houve algumas alterações, tais como: quatro cadeiras; e a instalação da seção feminina no Seminário da Glória. As cadeiras eram as seguintes: 1ª Cadeira: "Língua Nacional e aritmética" - Professor Doutor Melquíades da Boa Morte Trigueiro ${ }^{20} ; 2^{\mathrm{a}}$. Cadeira: "Francês, metódica e pedagogia" - Professor Doutor João Bernardes a Silva²1; $3^{\text {a }}$. Cadeira "Cosmografia e geografia, especialmente do Brasil" - Professor Doutor Américo de Ferreira de Abreu²2; e $4^{a}$. Cadeira "História Sagrada e Universal e Noções Gerais da Lógica Professor Doutor Antônio Augusto de Bulhões Jardim²3 (REIS FILHO, 1995, p. 151).

Além das modificações ocorridas quando da reabertura da Escola Normal de São Paulo, em 1877 "[...] são instaladas duas escolas primárias anexas, para que alunos de ambos os sexos nelas possam praticar metodologia. Neste caso, a preocupação do governo é apenas a de instalar" (BAUAB, 1972, p. 23).

No entanto, Bauab (1972, p.24) afirma que o "[...] professor da Anexa [era visto] com 'inferior' e, de certa forma, dependente dos demais docentes, permitindo-lhe votar na Congregação mas negando-Ihe o direito de substituir os professores da Escola Normal de São Paulo".

20 Melquíades da Boa Morte Trigueiro bacharelou-se em Direito pela Academia de Direito de São Paulo, em 1868. No âmbito de sua atuação profissional: atuou como professor da Escola Normal de São Paulo, entre 1876 e 1877; foi diretor da Escola Americana da Província de São Paulo, entre 1878 e 1881; foi diretor, em 1883, do Colégio Culto à Ciência, de Campinas-SP; e atuou como professor de um colégio particular de propriedade de Ernesto Vaz (DIAS, 2002). As datas e locais de nascimento e morte de Melquíades da Boa Morte Trigueiro não foram localizadas.

21 Até o momento, as únicas informações que pude localizar sobre João Bernardes da Silva foram: bacharelou-se em Direito pela Academia de Direito de São Paulo, em 1867; em 1877; ele foi nomeado professor interino da 1ª . Cadeiras da Escola Normal de São Paulo de São Paulo e, em 1878, foi nomeado professor da 2a . Cadeiras dessa instituição; e, em 1879, passou a atuar como juiz de Direito. (DIAS, 2002).

22 Américo Ferreira de Abreu nasceu 1831 e bacharelou-se em Direito pela Academia de Direito de São Paulo, em 1858. No âmbito de sua atuação profissional, Américo Ferreira de Abreu foi professor interino da $2^{a}$. Cadeiras da Escola Normal de São Paulo de São Paulo, em 1875, e foi examinador de professores de primeiras letras. Américo Ferreira de Abreu morreu em 1911 (PEREIRA, 2013). Até o momento, não foi possível localizar informações sobre o local de nascimento e morte de Américo Ferreira de Abreu.

23 Antonio Augusto Bulhões Jardim nasceu em 1852 e bacharelou-se em Ciências Jurídicas e Sociais pela Academia de Direito de São Paulo, em 1873. No ano de 1877, recebeu o título de doutor. No âmbito de sua atuação profissional, Antonio Augusto Bulhões Jardim: em foi nomeado, em 1876, professor interino da $4^{\text {a }}$. Cadeiras da Escola Normal de São Paulo de São Paulo; em 1878, foi nomeado Secretário interino da Escola Normal de São Paulo de São Paulo; e foi Deputado da Assembléia Provincial de Goiás (PEREIRA, 2013). 
Em 1878, a Escola Normal de São Paulo foi fechada novamente. Segundo Reis Filho (1995, p.151), embora tenha ocorrido um aumento do número de alunos matriculados e formados pela Escola Normal de São Paulo, esses motivos não foram suficientes para mantê-la aberta devido às dificuldades financeiras pelas quais essa escola passava.

Passados dois anos do fechamento da Escola Normal de São Paulo, foi "[...] reaberta pelo presidente da província Laurindo Abelardo de Brito, liberal e ex-aluno da escola, a sancionar em 25 de abril de 1880, como lei $n^{\circ}$. 130, o projeto apresentado por Inglês de Souza, um deputado de seu partido" (HILSDORF, 2008, p.6). Essa instituição de ensino "[...] deu origem ao atual Instituto de Educação 'Caetano de Campos', da Praça da República” (REIS FILHO, 1995, p.151).

A reabertura da Escola Normal de São Paulo representou uma tentativa de reorganização de forma sistemática de muitos dos anseios previstos com a criação dessa instituição em 1846. Segundo Reis Filho (1995), a organização dessa instituição era mais complexa que a anterior, pois nela havia um diretor "[...] subordinado diretamente ao Presidente da Província, possuía cinco cadeiras, distribuídas em três anos de curso" (p.151).

Em 30 de junho de 1880, o Regulamento de 1880... foi aprovado e, de acordo com ele, a finalidade da Escola Normal de São Paulo era "habilitar", gratuitamente, "[...] pessoas que se destinam ao magisterio publico primario" (SÃO PAULO, 1880, p. 3).

Quanto a formação "prática" do futuro professor primário, ocorria no $3^{\circ}$. ano, em que os aluno da Escola Normal deveriam aprender "[...] a conveniente aplicação das regras que devem ser observadas na pratica dos methodos" (SÃO PAULO, 1880, p. 6) nas aulas anexas à Escola Normal de São Paulo, uma vez por semana, sob a direção do professor da Cadeira de Pedagogia e do professor da Aula Anexa, de acordo com o Artigo 6. do Regulamento de 1880... .

O capítulo X, Artigo $120^{\circ}$. Ao $133^{\circ}$. do Regulamento de 1880... "Das aulas annexas", prescrevia o funcionamento de "[...] duas aulas destinadas a servir de curso de preparatórios a habilitar os alunos na pratica da regência das cadeiras" (SÃO PAULO, 1880, p. 27). De acordo com o Artigo 121, esse ensino prático ocorreria nas duas aulas anexas (seção masculina e feminina), que eram parte integrante da Escola Normal e eram fiscalizadas pelo Diretor da Escola Normal de São Paulo.

Os alunos da Escola Normal de São Paulo aprendiam por meio das aulas práticas como ensinar a leitura e escrita na "Aula anexa" à Escola Normal de São Paulo. A "Aula anexa" ocorria no curso primário anexo à Escola Normal de São Paulo.

O curso primário anexo à Escola Normal de São Paulo era dividido em duas seções, uma feminina e outra masculina. No curso primário as crianças da província aprendiam os rudimentos do ler, escrever e contar.

Silva Jardim nessa época lecionava na "Aula Anexa" a fim de completar sua renda e pagar as despesas quando ainda era estudante de Direito na Faculdade de Direito de São Paulo.

Bauab (1972) enfatiza a atuação de Silva Jardim como professor da "Aula Anexa", uma vez que ele colaborou para a "renovação dos métodos didáticos" e para um modo de pensar o ensino da leitura e escrita, por meio de um novo e revolucionário método da leitura, o método da palavração ${ }^{24}$ concretizado na Cartilha Maternal ou Arte da Leitura ${ }^{25}$, de João de Deus ${ }^{26}$. Principalmente num momento histórico educacional marcado pela utilização do

24 O método da palavração "[...] inicia-se esse ensino com palavras, que depois são divididas em sílabas e letras" (MORTATTI, 2004, p.123).

25 A Cartilha Maternal ou arte da leitura foi escrita pelo poeta, pedagogo e republicano João de Deus (1830-1896) e publicada, em 1876, em Portugal.

26 João de Deus nasceu em São Bartolomeu de Messines no Algarve, Portugal, em 8 de Março de 1830 e morreu em Lisboa em 11 de Janeiro de 1896. Estudou Direito na Universidade de Coimbra entre 1849 e 1859. Foi poeta e tinha Antero de Quental como amigo. Autor da Cartilha maternal ou arte da leitura que se baseava no método da palavração (BRAGA, s.d). 
[...] método greco-romano de iniciar o ensino da leitura pela aprendizagem das letras do alfabeto, seguida toda a combinação silábica possível, as lições de Silva Jardim representavam de fato o 'alvorecer da didática' em São Paulo, como a elas se refere João Lourenço Rodrigues (REIS FILHO, 1995, p.154).

Nessa nova conjuntura da Escola Normal de São Paulo, ocupavam cada uma das cinco Cadeiras, os seguintes professores: Doutor Vicente Mamede de Freitas ${ }^{27}$ - 1ª . Cadeira: "Gramática e Língua Nacional"; 2a . Cadeira "Aritmética e Geometria"- Professor Doutor "Godofredo José Furtado28"; $3^{a}$. Cadeira: "História e Geografia"- Professor Doutor José Estácio Correia de Sá e Benevides²9; e 4a. Cadeira "Pedagogia e Metodologia" - Professor Doutor Inácio Soares Bulhões Jardim; e 5ª Cadeira: "Francês, Física e Química" - Professor Doutor Paulo Bourroul30 (REIS FILHO, 1995, p. 152).

Com a reabertura da Escola Normal de São Paulo em 1880 houve as seguintes mudanças: o curso foi ampliado para três anos; as aulas que antes eram destinadas apenas ao sexo masculino passaram a ser "mistas"; a criação do curso preparatório anexo, com uma classe destinada para os homens e outra para as mulheres (REIS FILHO, 1995, p.153). Ainda, segundo Reis Filho (1995), a Escola Normal de São Paulo de 1880 passou a

[...] desempenhar papel de relativa importância da inovação dos processos de ensino. A ampliação de seu plano de ensino, enriquecido com um elenco de matérias científicas e com três anos de duração [que] possibilitava uma melhor formação geral ou propedêutica do futuro professor primário (p.152).

Segundo Reis Filho (1995, p.152), com a reorganização dessa instituição, foi dada ênfase à "inovação dos processos de ensino" e "[...] a atuação de alguns professores renovava em suas disciplinas os métodos de ensino. É o caso de Silva Jardim". A esse respeito, Hilsdorf (2008, p.93), ressalta que, a partir da

[...] década de 1880, de abertura do país às inovações pedagógicas que eram associadas na Europa e nas Américas à educação escolar atualizada, representadas aqui, entre outras aqui, entre outras, pela inclusão das matérias científicas e a adoção e adoção do método intuitivo.

27 Vicente Mamede de Freitas: Nascido em São Paulo, 1836, Vicente Mamede de Freitas bacharelou-se em Direito em 1855, pela Academia de Direito de São Paulo. No ano de 1856, passou a dirigir o Colégio Culto à Ciência, em Campinas-SP. Nesse mesmo período, fundou um colégio na cidade de São Paulo. No ano de 1859, defendeu uma tese na área do Direito, pela qual recebeu o título de Doutor. Em 1860 , atuou como promotor público e, entre 1864 e 1866, atuou como Deputado da Assembleia Provincial de São Paulo. Entre os anos de 1880 e 1882, Vicente Mamede de Freitas foi Diretor da Escola Normal de São Paulo de São Paulo e Inspetor Geral da Instrução Pública da Província de São Paulo. Após sua atuação na Escola Normal de São Paulo de São Paulo, no ano de 1882, foi aprovado em concurso para o cargo de lente substituto da Academia de Direito de São Paulo, passando, em 1887, ao cargo de lente catedrático. Ainda no âmbito de sua atuação junto a Academia de Direito de São Paulo, foi nomeado, em 1902, vice-diretor dessa instituição, e, em 1904, diretor. Vicente Mamede morreu em São Paulo, em 1908. (FACULDADE..., s.d.)

28 Godofredo José Furtado: Nascido em Godofredo Furtado: Nascido em 9 de junho de 1851 em Caxias.Foi professor da cadeira de Matemática da Escola Normal de São Paulo. (POLIANTEIA, 1946).

29 José Estácio Correia de Sá e Benevides: Nascido em 1856, em São Paulo, José Estácio Correia de Sá e Benevides diplomou-se, em 1878, pela Escola Normal de São Paulo e, em 1879, bacharelou-se em Ciências Jurídicas e Sociais pela Academia de Direito de São Paulo. No ano de 1880, foi nomeado professor interino da 3ª . Cadeiras da Escola Normal de São Paulo de São Paulo e, entre 1884 e 1887, foi diretor da Escola Normal de São Paulo de São Paulo. José Estácio Correia de Sá e Benevides morreu em São Paulo, em 1914. (POLIANTÉIA, 1946; PEREIRA, 2013) 30 Paulo Bourroul: Nascido em Nice, em 1855, Paulo Bourroul fez os estudos elementares no Brasil e depois diplomou-se médico em Bruxelas-Bélgica, na década de 1870. Em 1879, voltou a residir no Brasil, quando prestou o Exame de Proficiência da Faculdade de Medicina do Rio de Janeiro. No ano seguinte, 1980, foi nomeado professor interino da $2^{a}$. Cadeiras da Escola Normal de São Paulo de São Paulo, porém, com a recusa do professor convidado para atuar junto a 5a. Cadeiras (Francês, Física e Química) da Escola Normal de São Paulo de São Paulo, Paulo Bourroul assumiu o cargo de professor efetivo dessa Cadeiras. Paulo Bourroul atuou como professora da $5^{a}$. Cadeiras da Escola Normal de São Paulo de São Paulo até o ano de 1882, quando foi nomeado professor substituto da Academia de Direito de São Paulo. Também no ano de 1882, Paulo Bourroul foi nomeado diretor da Escola Normal de São Paulo de São Paulo, cargo que ocupou até 1884. Paulo Bourroul morreu no ano de 1941, aos 86 anos, em São Paulo. (POLIANTÉIA, 1943; PESTANA, 2011). 
Com a modificação proposta pela Lei n.59 de abril de 1884, a Escola Normal de São Paulo passou a ter seis cadeiras de ensino, dentre as quais a cadeira de ensino ocupada por Silva Jardim. São elas: "1ª. Grammatica e Lingua Nacional"- Antonio da Silva Jardim; "2a . Arithmetica e geometria" - Godofredo José Furtado; "3․ Elementos de Cosmographia, Geografia e Historia"; "4 4 . Pedagogia, methodologia e instrução religiosa"- Antonio da Silva Jardim (substituto interino em 1884) - Manoel José Trancoso da Lapa; "5a. Noções de physica e Chimica"- Cypriano José de Carvalho; e "6a'. Grammatica e Lingua Franceza"- Arthur Gomes; Carlos Marcondes de Toledo Lessa" (SÃO PAULO, 1884).

A primeira Cadeira de "Grammatica e Lingua Nacional" foi ocupada por Silva Jardim em 1884, somente passou assim ser chamada com a alteração da Lei n. 59, de abril de 1884, que modificou o Artigo 5. do Regulamento de 1880... da Escola Normal de São Paulo .

Silva Jardim permaneceu como professor da Primeira "Grammatica e Lingua Nacional" até o ano de 1885, quando se mudou para cidade de Santos/SP em virtude dos falecimentos de sua filha e de seu sogro. Segundo D’Avila (1946), o sucessor de Silva Jardim foi professor Júlio Ribeiro¹, que passou a ocupar a cadeira de "Grammatica e Lingua Nacional", porém, D’Avila (1946) citando as palavras de João Lourenço Rodrigues, destaca que

[...] Júlio Ribeiro 'não tinha os mesmos dotes didáticos do seu antecessor. Em vez de manter as aulas práticas que Silva Jardim estabelecera com tantos resultados, Júlio Ribeiro seguiu o sistema já em si condenável. Sua exposição era prolixa, desordenada, cortada de divagações sobre assuntos estranhos à aula' (1946, p.93)

Segundo Bauab (1972) com o pedido de licença de Ignácio Soares Bulhões Jardim, no dia 4 de junho de 1884, que ocupava a $4^{a}$. Cadeira "Pedagogia, methodologia e instrução religiosa". Silva Jardim passa a ocupar essa cadeira como professor substituto interino até a saída definitiva de Ignácio S. Bulhões Jardim.

Silva Jardim era contrário ao ensino mútuo prescrito no Artigo $4^{\circ}$. da Constituição de 1824. Para ele, seria necessária a formação dos professores primários de acordo com o método de ensino intuitivo.

Segundo Valdemarin (2004), o método de ensino intuitivo estava diretamente relacionado à observação e a ideia de que a escola deveria ensinar os conteúdos vinculados ao cotidiano das crianças, ou seja, os elementos da realidade do aluno eram trazidos para os exercícios da sala de aula. Tal método pode ser percebido nos exercícios que Silva Jardim propunha para o ensino da leitura e escrita.

A respeito desse método, Valdemarin (2008) ressalta que o manual Primeiras lições de Coisas, de Calkins, foi um

[...] marco significativo da tentativa de implantar o método de ensino intuitivo no ensino brasileiro, que remonta ao decênio de 1880, expressa a pretensão de adotar um método didático consoante com a renovação pedagógica em curso na Europa e nos Estados Unidos da América, cujos efeitos poderiam ser irradiados para toda a sociedade, implementando as transformações sociais, políticas e econômicas almejadas nas últimas décadas do Império. (p.89-90).

31 Júlio César Ribeiro Vaugham nasceu no dia 16 de abril de 1845 em Sabará (MG) e faleceu no dia $1^{\circ}$ de novembro de 1890 em Santos (SP). Foi professor na Escola Normal de São Paulo e ocupou a Cadeiras de Latim no Curso Anexo da Faculdade de Direito. Além disso, teve publicado o livro Grammatica portugueza (1881) (POLIANTEIA, 1946). 
Embora o método intuitivo somente tenha se tornado oficial com a Reforma "Caetano de Campos", em 1890, pode-se observar que Silva Jardim já apontava os benefícios desse método para o desenvolvimento mental das crianças. Além disso, Silva Jardim ressaltava a importância da função do professor no âmbito do ensino pelo método intuitivo, pois, segundo ele, o professor bem preparado poderia melhor desenvolver exercícios e atividades, de acordo com as necessidades de seus alunos.

[O] ensino da lingua numa escola Normal deve terminar pela parte pedagogica, de indicação dos meios praticos de ensinarem-se as diversas disciplinas. Será de summa vantagem que possa esse ensino ser acompanhado de exercícios praticos nas aulas annexas que devem servir de norma aos futuros mestres. (JARDIM, 1884, p.21, grifos meus).

\section{Silva Jardim e a divulgação do "novo e científico" método "João de Deus" para o ensino da leitura e escrita}

No modo de pensar a "arte da leitura", Silva Jardim destaca a contribuição do poeta positivista João de Deus, autor da Cartilha Maternal ou "arte da leitura", que, segundo Silva Jardim, revolucionou o modo de ensinar a "arte da leitura". Silva Jardim, que, como informei, foi um dos divulgadores do método "João de Deus", e com o poeta João de Deus chegou a trocar correspondências sobre os benefícios da utilização da Cartilha maternal.

Segundo Mortatti (2000), o "método João de Deus" para o ensino inicial da leitura concretizado na Cartilha Maternal ou "arte da leitura" começou a circular no Brașilı a partir dos anos iniciais da década de 1880, principalmente nas províncias de Șão. Pạulo. e do Espírito Santo. Segundo Trindade (2004), a Cartilha maternal também foi adotada oficialmente no estado do Rio Grande do Sul.

Boto (1997) destaca que o professor João de Deus contribuiu para a inovação pedagógica em Portugal, pois seu método iniciava-se pelo processo da leitura pela palavra,

[...] o que torna a lógica do aprendizado da leitura semelhante à lógica da fala; em ambos os casos, o ponto de partida seria o significado [...] nessa medida, pode ser considerado como um antecedente do método ou até precursor do método global ou analítico desenvolvido por Decroly no princípio do século XX. (p.148).

Esse movimento de propagação e utilização do "método João de Deus" em São Paulo estava em sintonia com as ideias e os modelos pedagógicos em vigência, nesse mesmo momento histórico, em Portugal e no Brasil. Segundo Boto (1997), "Geração de 1870" de intelectuais e educadores,

[...] foi responsável por evidenciar esse "atraso" das civilizações e defendia a educação como um meio de superar essa ignorância, ou seja, era "ilustrando" o povo que a civilização progrediria. Nesse aspecto, João de Deus cumpria os requisitos adequados ao clima de época. O título de sua cartilha - "Cartilha Maternal ou "arte da leitura" — "[...] é já por si revelar do desejo subliminar do autor quanto à proposição de uma aliança entre a escola e família, em nome da instrução.". (p.142).

Porém, segundo Silva Jardim, não bastaria ensinar a leitura por meio da Cartilha Maternal, seria necessário "[...] para sua efficacidade, além da maneira especial de seu ensino, esse processo pede pronuncia clara e gradativa dos vocábulos, e a explicação dos sentidos das palavras empregadas" (SILVA JARDIM, 1884, p.13). As palavras utilizadas deveriam estar relacionadas com o cotidiano da criança, uma vez que Silva Jardim julgava necessária a adaptação do método de acordo com as crianças de cada lugar. 


\section{Conclusão}

O pensamento de Silva Jardim sobre o ensino da leitura e escrita está diretamente relacionado ao Positivismo em que se destaca o papel dos bons sentimentos na formação da criança e na civilização do povo, além da defesa pela instauração da República, regime político que segundo Silva Jardim, possibilitaria ao Brasil sair do atraso em comparação aos países europeus e se tornar o "novo mundo". Para tanto seria necessária à reforma do ensino da língua materna pautada no método da palavração em contraposição ao método da soletração utilizado à época.

A atuação de Silva Jardim colaborou, no Império, para a sistematização do que na República denominou-se escola, e contribuiu para a reflexão de que pensar em alfabetização é pensar em todo seu entorno político, econômico, cultural e social, ou seja, multidisciplinar.

Por fim, embora menos visível, essa face não é menor ou menos importante no âmbito de seu pensamento, pois, para Silva Jardim, pensar o ensino de língua materna era uma questão política (de base republicana e positivista).

\section{Referências}

AGUIAR, L. Antonio da Silva Jardim: o herói da Proclamação da República. Rio de Janeiro: Ao livro técnico, 1989. BEZERRA, C. E. O. Adolfo Caminha: um polígrafo na literatura brasileira do século XIX (1885-1897). São Paulo: Cultura Acadêmica, 2009.

BOTO, C. J. M. C. R. Ler, Escrever, Contar e se Comportar: a Escola Primária como Rito do Século XIX Português (1820-1910). 1997. Tese (Doutorado em História Social) - Faculdade de Filosofia, Letras e Ciências Humanas, Universidade de São Paulo, São Paulo, 1997.

BRASIL. Constituição brasileira de 1924. Disponível em: <http://www.planalto.gov.br/ccivil_03/constituicao/ constitui\%C3\%A7ao24.htm>.Acesso em: 08/07/2014.

CAMPOS, M. C. S. S. C. Formação do magistério em São Paulo: do império a 1930. Caderno de Pesquisa, São Paulo: CERU, fev. 1990. p. 5-16.

CARVALHO, J. M. Nação e cidadania no império: novos horizontes. Ed. Civilização Brasileira, 2007.

CARVALHO, M. M. C. de. A escola e a república e outros ensaios. Edusp: Bragança Paulista, 2003.

CRUZ, H. F. São Paulo em papel e tinta: periodismo da vida urbana (1890-1915). São Paulo: EDUC: FAPESP; Arquivo do Estado de São Paulo; Imprensa Oficial, 2000.

D'AVILA, A. Antônio da Silva Jardim. In: POLIANTÉIA comemorativa do $1^{\circ}$ centenário do Ensino Normal de São Paulo. São Paulo: [s. n], 1946. p. 89-98.

DORNAS FILHO, J. Silva Jardim. São Paulo: Cia Editora Nacional, 1936.

FARIA FILHO, L. M. Instrução Elementar no século XIX. In: LOPES, Eliane M. T., FARIA FILHO, Luciano M. e VEIGA, Cynthia G. 500 anos de educação no Brasil. Belo Horizonte: Autêntica, 2003.

FERNANDES, M. F. L. A esperança e o desencanto: Silva Jardim e a República. São Paulo: Humanitas; FAPESP, 2008.

GUZZO, M. A. D. Silva Jardim: política, economia, questão social, abolicionismo e racismo. São Paulo: Icone Editora, 2003.

HISLDORF, M. L. S. Cultura escolar/cultura oral em São Paulo (1820-1860).VIDAL, Diana Gonçalves; HISLDORF, Maria Lúcia Spedo. Brasil 500 anos: tópicas em história da educação. Autêntica: belo Horizonte, 2001. 
HISLDORF, M. L. S. Francisco Rangel Pestana: jornalista, político, educador. 1986. 343 f. Tese (Doutorado em Educação)- Faculdade de Educação, Universidade de São Paulo, 1986.

HISLDORF, M. L. S.. A Escola Normal de São Paulo, entre o nós e o outro. In: ARAUJO, José Carlos Souza; FREITAS, Anamaria Gonçalves Bueno; LOPES, Antônio de Pádua Carvalho(Org.). As Escolas Normais no Brasil: do Império à República. Campinas: Editoa Alínea, 2008.

JARDIM, Antonio da Silva. Reforma do ensino da língua materna (1884), de Antonio da Silva Jardim. São Paulo: typ. Seckler, 1884. (Conferência realizada no dia 22 de abril de 1884 na Escola Normal de São Paulo)

JARDIM, Antonio da Silva. Relatorio apresentado a S.Ex. o Sr. Presidente da província do Espirito- Santo Dr. H.M. Inglez de Sousa sobre a historia e resultado da propaganda do methodo de leitura João de Deus. Vitoria: Typ. da Provincia, 1882.

LE GOFF, J. História e memória. Trad. Bernando Leitão...[etal.]. 5.ed. Campinas: UNICAMP, 2003.

LEÃO, J. Silva Jardim: apontamentos para a biographia do illustre propagandista, hauridos nas informações paternas e dados particulares e officiaes. Rio de Janeiro: Imprensa Nacional, 1895.

LEITE, A. R. P. Silva Jardim: o esquecido. São Paulo: Impr. Pannartz, 1984.

LIMA, H. F. Perfil político de Silva Jardim. São Paulo: Cia Editora Nacional; Brasília: INL, 1987.

LIMA SOBRINHO, B. Silva Jardim: discursos, opúsculos, manifestos. Niterói: Imprensa Universitária. 1973.

MAGNANI, M. R. M. Os sentidos da alfabetização: a "questão dos métodos" e a constituição de um objeto de estudo (São Paulo: 1876/1994). 1997. 389f. Tese (Livre-Docência em Metodologia do Ensino de $1^{\circ}$ Grau: Alfabetização) - Faculdade de Ciência e Tecnologia, Universidade Estadual Paulista, Presidente Prudente. 1997.

MORTATTI, M. R. M. Os sentidos da alfabetização: São Paulo 1876/1994, São Paulo: Editora UNESP, 2000a.

MORTATTI, M. R. M. (Org.). Alfabetização no Brasil: uma história de sua história. São Paulo: Cultura Acadêmica; Marília: Oficina Universitária, 2011.

MORTATTI, M. R. M. Cartilha de alfabetização e cultura escolar: um pacto secular. Cadernos CEDES, ano XIX, n 52, nov. 2000b.

MORTATTI, M. R. M. Letrar é preciso, alfabetizar não basta... mais?. In: SCHOLZE, Lia; ROSING, Tânia (org.). Teorias e Práticas do Letramento. Brasília: INEP; Passo Fundo: Ed. UFPF, 2007. p. 155-168.

MORTATTI, M. R. M. Ensino de língua e literatura no Brasil: repertório documental republicano. Marília. 2003. (Digitado).

MORTATTI, M. R. M. Notas sobre linguagem, texto e pesquisa histórica em educação. História da educação. Pelotas, v. 6, p. 69-77, out. 1999.

MORTATTI, M. R. M. Bibliografia brasileira sobre história do ensino de língua e literatura no Brasil (2003-2011), 2012. (Digitado).

MÓISES, M. História da literatura brasileira: realismo e simbolismo. Edição Revista e atualizada. Editora Cultrix: São Paulo, 2001.

PASQUIM, Franciele Ruiz. Reforma do ensino da lingua materna (1884), de Antonio da Silva Jardim, na história do ensino de leitura e escrita no Brasil. 2013. 150f. Dissertação (Mestrado em Educação) - Faculdade de Filosofia e Ciências, Universidade Estadual Paulista, Marília, 2013.

PASQUIM, Franciele Ruiz. Um estudo sobre Cartilha infantil pelo methodo analityco [1910?], de Carlos Alberto Gomes Cardim (1875-1938). 2010.103p. Trabalho de Conclusão de Curso (Licenciatura em Pedagogia) Universidade Estadual Paulista, Faculdade de Filosofia e Ciências, Marília, 2010. 103p.

PASQUIM, Franciele Ruiz. Bibliografia de e sobre Carlos Alberto Gomes Cardim (1875-1938): um instrumento de pesquisa, 2010. (Digitado) 
PASQUIM, Franciele Ruiz. Bibliografia de e sobre Antonio da Silva Jardim (1860-1891): um instrumento de pesquisa, 2012. (Digitado).

POLIANTÉIA comemorativa do 1․ Centenário do Ensino Normal em São Paulo: 1846-1946. São Paulo: [s.n], 1946.

QUEIROZ, M. V. Paixão e morte de Silva Jardim. Rio de Janeiro: Civilização Brasileira, 1967.

QUEIROZ, M. V. Uma garganta e alguns niqueis: historia de Silva Jardim, o heroi da propaganda republicana. Rio de Janeiro: Aurora, 1947.

REIS FILHO, C. A educação e a ilusão liberal. São Paulo: Cortez: Autores Associados, 1981.

REVISTA ILUSTRADA. Rio de Janeiro, anno 3, 1878. Publicada por Angelo Agostini. Disponível na seção "Obra Raras da Biblioteca Nacional" em: www.bn.com.br. Acesso em: 10 de janeiro de 2013.

RIBEIRO, J. O que é positivismo. $7^{\text {a }}$. edição. Editora Brasiliense:1988.

RICCI, M. L. S. R. Ação e pensamento em Silva Jardim. Campinas: PUC, 1987.

SÃO PAULO. Regulamento da escola normal expedido aos 30 de junho de 1880 pelo conselheiro Laurindo Abelardo de Brito: autorizado pela disposição do Artigo $1^{\circ}$ da lei n $n^{\circ} 130$ de 25 de abril de 1880. São Paulo.

TANURI, L. M. O ensino normal no estado de São Paulo: 1890-1930. São Paulo: Universidade de São Paulo, Faculdade de Educação, 1979.

TANURI, L. M. História da formação de professores. Revista Brasileira de Educação, n. 14, maio-agosto 2000, p. 61-88.

VAINFAS, R. (Org.). Dicionário do Brasil Imperial (1822-1889). Rio de Janeiro: Objetiva, 2008.

VALDEMARIN, V. T. O método intuitivo: Os sentidos como janelas e portas que se abrem para um mundo interpretado. In: ALMEIDA, Jane Soares de; SOUZA, Rosa Fátima; VALDEMARIN, Vera Teresa; SAVIANI, Dermerval. O legado do século XIX. 2 ed. rev.e ampl. Campinas: Autores Associados, 2006. p. 86-127.

VIEIRA, M. P. A; PEIXOTO, M. R. C; KHOURY, Y. M. A. 4. ed. A pesquisa em história. São Paulo: Ática, 2005.

Recebido em: 20/06/2020

Aceito em: 30/10/2020 